\title{
The Sacred Freespace
}

\author{
Francesco Costanzo ${ }^{1}$, Gaspare Oliva ${ }^{2}$ \\ ${ }^{1}$ Associate professor, Università della Campania Luigi Vanvitelli, Dipartimento di Architettura e Disegno \\ Industriale \\ ${ }^{2}$ Cultore della materia, PhD, Università della Campania Luigi Vanvitelli, Dipartimento di Architettura e Disegno \\ Industriale
}

\begin{abstract}
Keeping in the background the search for geometric-mathematical exactness, that in different cultures oversees the construction of sacred building and starting from the need to isolate it in order to make its "true form" recognizable, this paper analyzes features and conditions of the spaces of the city where different isolated and formally defined religious buildings coexist, as happens, for example, in Italian squares characterized by opposition between Cathedral and Baptistery. The Campo dei Miracoli in Pisa is assumed as a paradigm of in-between consecrated space in which several isolated buildings determine a tensional space and define a unique and unrepeatable configuration individuated among the multiple possible combinations of positions and architectural figures that is, according to Leibniz, expression of the idea of infinity. This kind of space looks for exactness not through closed forms but through relationships, positions and alignments of standing buildings and its rarefaction is directly connected with the idea of open city dispersed in nature proposed by modern architecture.
\end{abstract}

(C) 2020 The Authors. Published by IEREK press. This is an open access article under the CC BY license (https://creativecommons.org/licenses/by/4.0/).

\section{Keywords}

Exactness as Utopia; Freespace; Dispositio; Modern project

\section{Sacred mathematics: exactness as representation of divine}

The "mathematics of the sacred building" - the assumption of an Euclidean repertory for the shape of the building is not simply a representative expression of the divine ideal, its identification with an exact form. It is above all the way in which man has decided to interpret the tem (snippet of the finite within the infinite): the difference between the extraordinary nature of sacred space and the ordinariness of civil space (Costanzo 2011). Temenos-templeenclosure is therefore a highly defined place from the formal point of view and a contraction of undifferentiated space. In this sense the exactness is a way for reaching utopia.

In both western and eastern culture, the type-morphological definition of the sacred building pursues formal exactness and therefore uses mathematics. In particular, there are two different ways in which it can operate on the architecture's formalization process.

The first is a closed and continuous way that focuses on figuration and it is aimed to concluded, perfect and finite form. In other words, we could say that it seeks perfection through finiteness by pursuing harmonious mathematicalgeometric ratios leading to a self-regulated and autonomous formal balance. This search for figural absoluteness is clearly explained in theoretical works by Leon Battista Alberti and in buildings by coeval architects such as Bramante. The first, in his treatise about the composition of the church, in a context influenced by the Neo-Platonism of the late 
fifteenth century, reflects on the central plan intended as the "nucleus of the ideal city"; while the second can realize in the Todi countryside, in lacking of specific site's constraints, a central-plan Christian temple characterized by exact proportions (Figure 1). However, this mode does not only concern Christian architectures, but it also extends to the space of other religions, as happens in the Ottoman mosques descending from the great paradigm of Haghia Sophia in Istanbul.

The second is an open and discontinuous mode, focused on repetition evoking the limitlessness through the obsessive iteration of an architectural element. It recurs in Islamic worship buildings assuming the archetype of the hypostyle. We refer in particular to architectures we can find in the Arab or North African areas, that are not addressed to the construction of a central focal point through symmetry, but they rather want to realize homogeneous space, tending to isotropic condition, hierarchized by the mere presence of the significant worship places, such as the mihrāb or the minbar, and which is sometimes combined with the idea of the courtyard. As happens in the emblematic example of the Mosque of Cordoba, mathematics governs the hypostyle's discontinuous forms, a three-dimensional colonnaded space filling the emptiness of the architectural box (Figure 2).

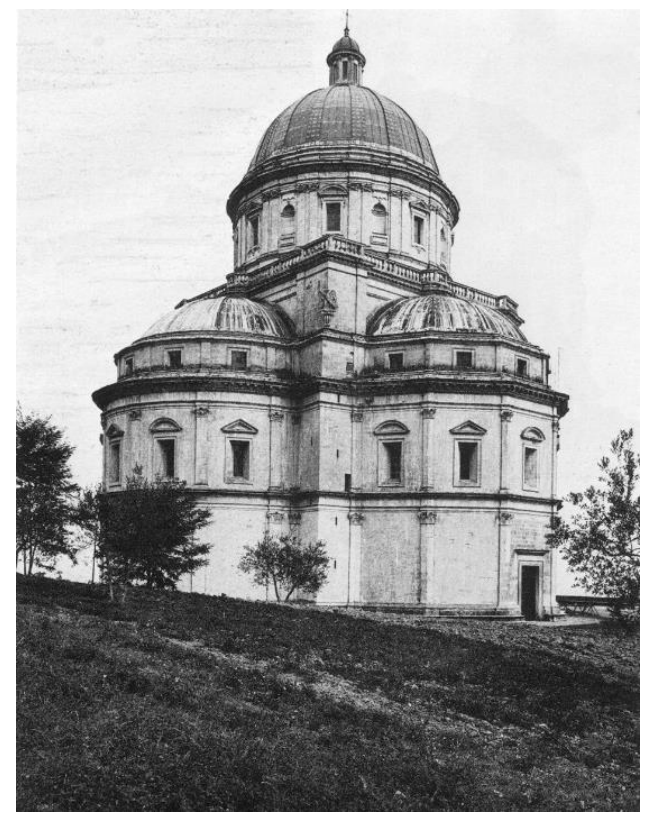

Figure 1. Todi, Santa Maria della Consolazione temple attributed to Bramante

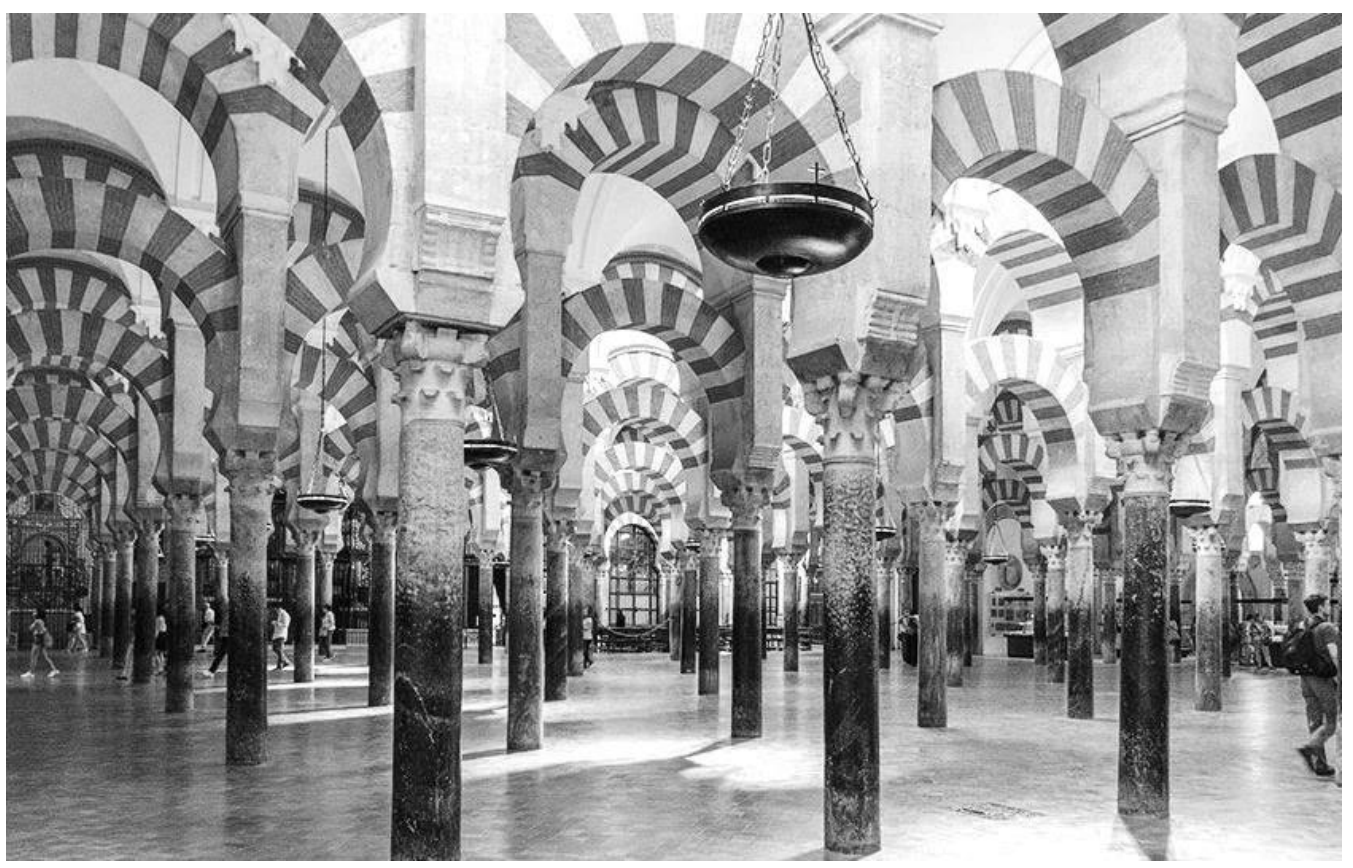

Figure 2. Cordoba, Mosque, interior space 
As we go through space we perceive the idea of multiplicity, which is a modern way for representing unity, a condition of openness, of non-finiteness deriving from the assumption of grid as a formal device, as an abstract matrix.

In lingering on the relationship between architectural composition and sacred space, we don't want to consider this relationship from the point of view of the sacred building constitutive aspects, historically determined by interpreting the relationship between the community of the faithfuls / ecclesia and rite / liturgy (Martì Arìs, 1990), but we want to explore the correspondences that space and sacred building can establish with the city and with the landscape.

\section{Sacred ground: the Campo dei Miracoli as a paradigm}

Starting from the sacred building isolation, aimed at recognizing the "true form" of the building (Leonardo da Vinci), we therefore refer to spaces of the city to be intended as place of separation in which several isolated and formally defined religious buildings coexist. On the one hand, the reference is to the urban condition of Italian squares based on the opposition between the Cathedral and the Baptistery, such as in Parma or Pistoia. On the other hand, we refer to the territorial contexts in which religious artefacts interact with nature and landscape, as happens in "Valle delle Ferriere" between Ravello and Scala in the Amalfi coast, that is a geographical entity exalted by the confrontation at a distance of medieval churches' apses dotting the two sides.

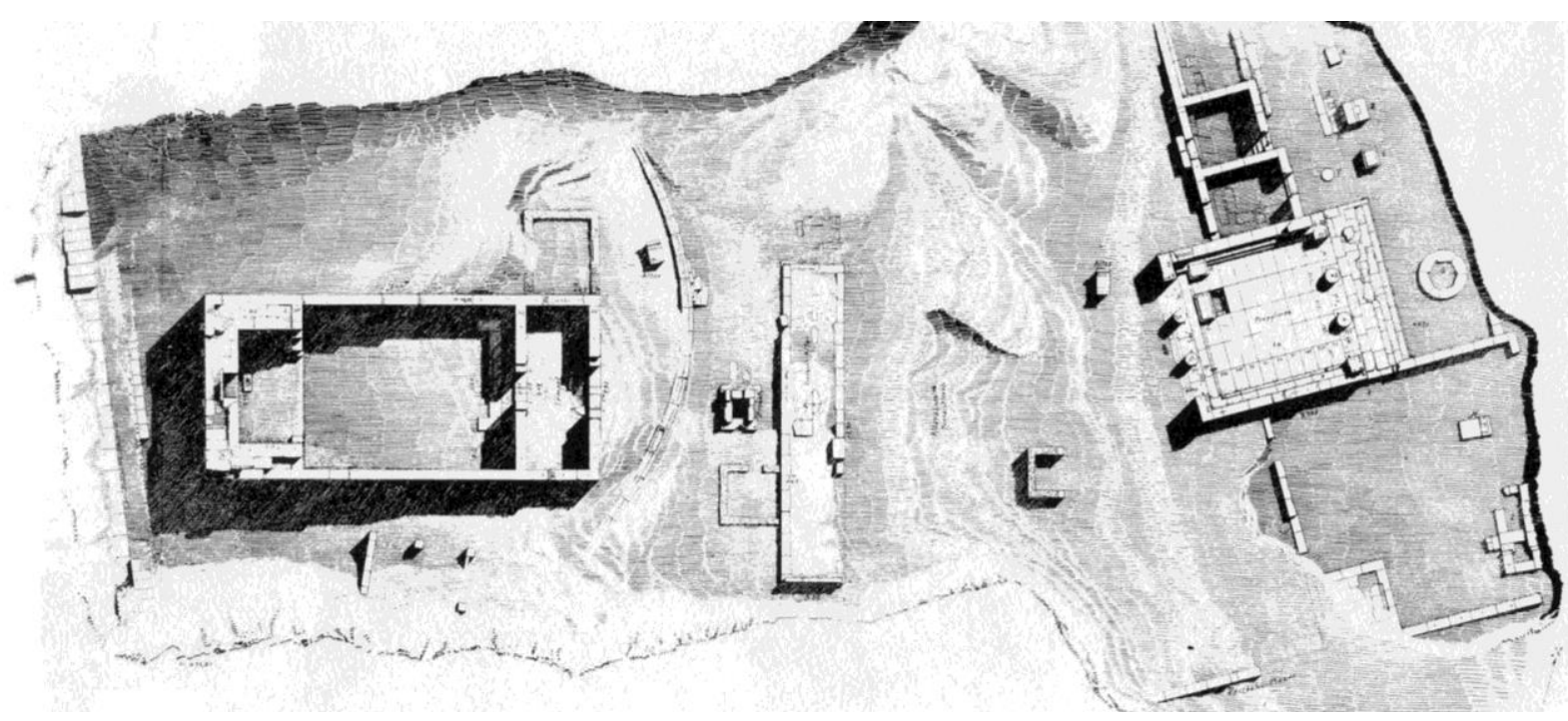

Figure 3. Selinus, Sacred Enclosure of Demetrios Malophoros. Plan (by Koldewey and Puchstein)

But in particular, we would like to redefine a geneaology of the modern sacred and public space, coming from those conditions in which unity is revealed through the ground, itself sacred. In the Athens acropolic space or in the system of sacred enclosures - like the Demetrio's near Selinunte (Figure 3) or the commemorative space in Suleymaniye complex by Sinan (Günay, 1998) (Figure 4) - the place is identified not only with the identity of the architectural artefact but also with the dispositio according to which several buildings, several architectural figures, define a discontinuous form of space. As Doxiadis demonstrates in his analysis of Athens Acropolis (Figure 5), the space revealed by the propylaea - in which the Parthenon and the Erechtheum, the temple of Demetrios, the small altar and the votive stele stand as isolated buildings - responds to precise alignments and geometric canons establishing their positions (Doxiadis, 1972).

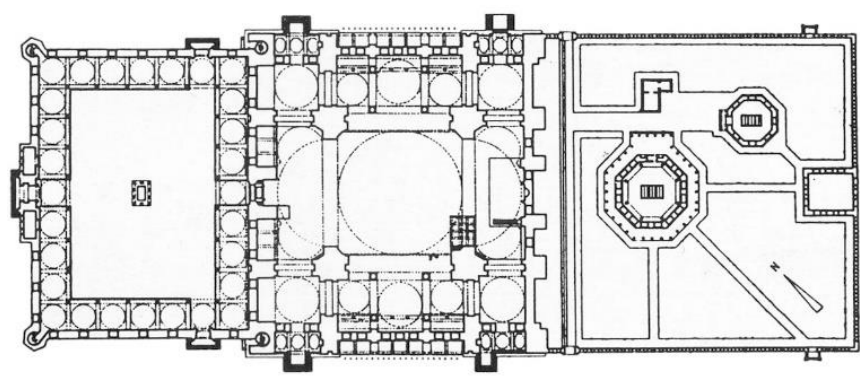

Figure 4. Istanbul, Suleymaniye Complex, 1550-1557. Plan (by Günay)

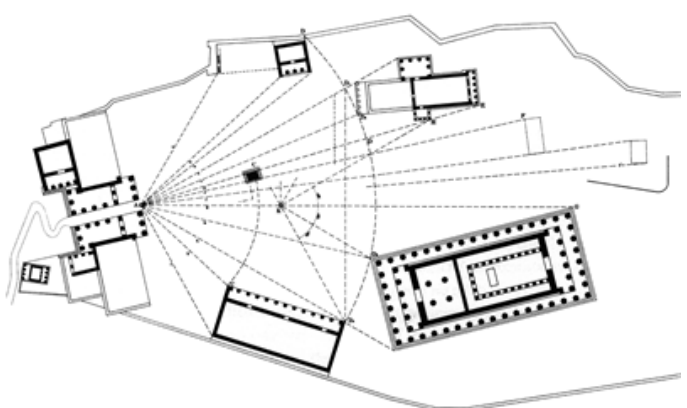

Figure 5. Athens, Acropolis III, after 450 B.C. Plan (by Doxiadis) 


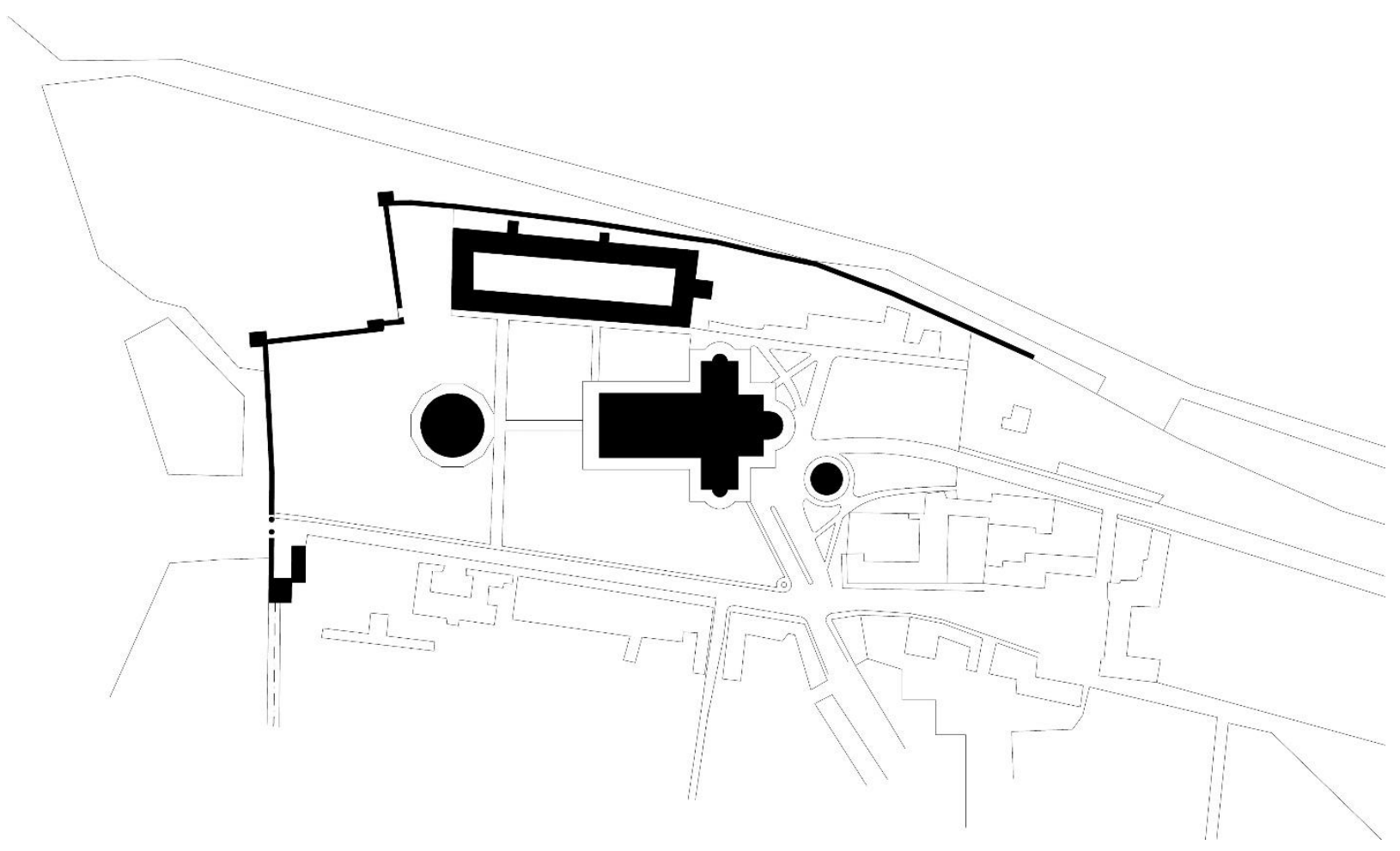

Figure 6. Pisa, Campo dei Miracoli. XI-XIV Century. Plan (by Costanzo 2007)

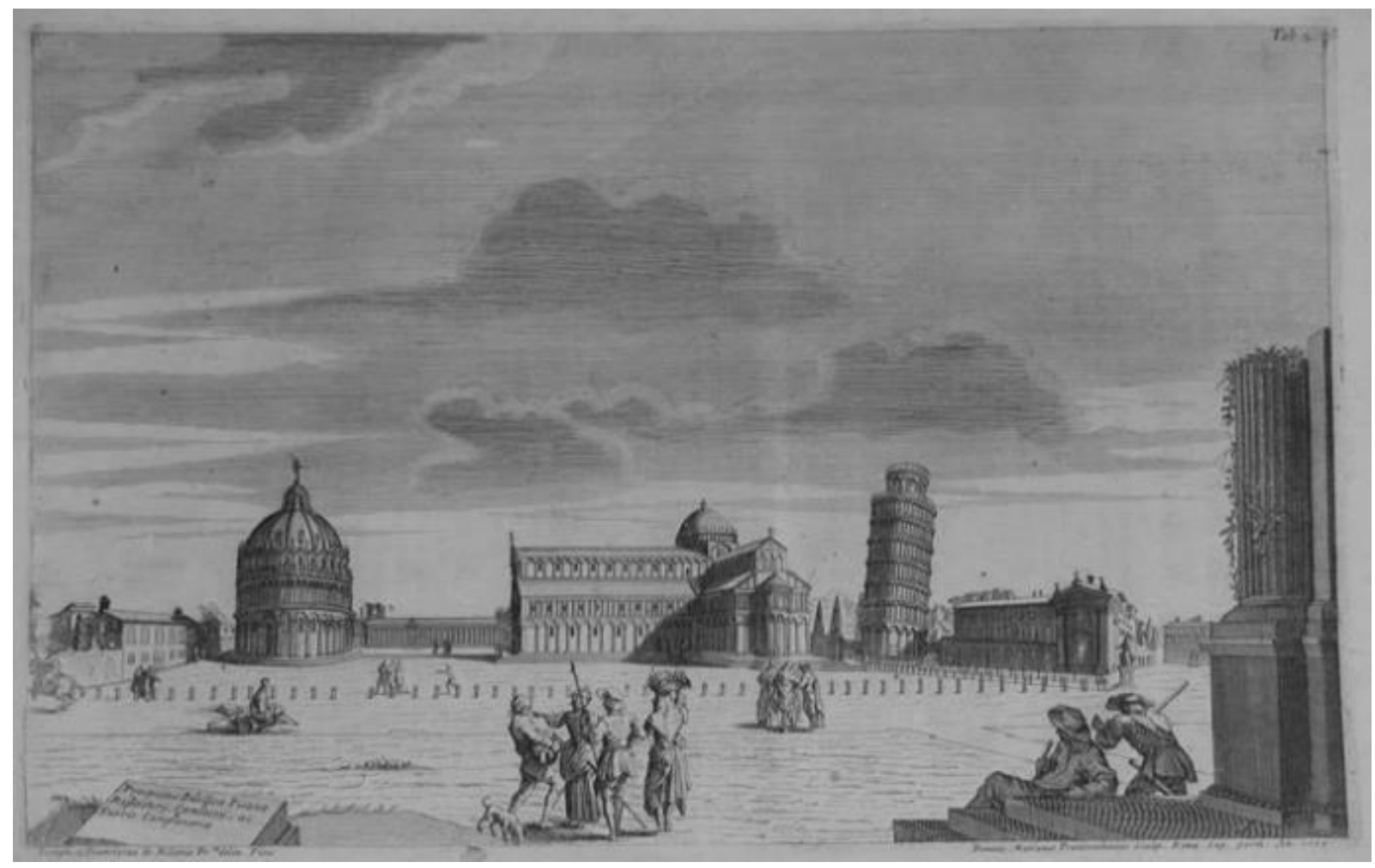

Figure 7. Pisa, Campo dei Miracoli. XI-XIV Century. Prospectus Basilicae Pisanae, Baptisterij, Coemeterij, ac Turris Campanariae, 1705

These insulations act on a space defined by a rampart or by an enclosure tending to declare the autonomy of these places from the recurring urban forms.

This search for autonomy oversees that experience in the history of city and represents the most important cornerstone for subsequent developments. In the Campo dei Miracoli in Pisa, considered as unicum and as a paradigm of acropolic dispositio, at the beginning of the year 1000, in a rare moment of political equilibrium in which Pisa was the first maritime city of the Mediterranean Sea, the builders tried to interpret the solicitations coming from different cultures creating a synthesis between them (Costanzo, 2007). 
Here the construction of a new urban part corresponds to a place beyond the city limits - the limes overcoming that is proper of the modus odiernus (Bodei, 2016) - to define an urban outpost without the conditionings that the consolidated city, as testimony of an urban history, implied with its urban morphologies (Figure 6).

On the consecrated lawn, that was an ancient place of burial, the figures of the remarkable religious architectures are impressed: the Cathedral, the Baptistery, the Campanile, the Camposanto (Figure 7). The isolation of artefacts, that are formally distinct, shows a single stylistic register, despite the construction of the Campo at different times (the Cathedral began in 1064, the Baptistery in 1152, the Campanile in 1164, the Camposanto in the Fourteenth Century). This unity derives from Buscheto's ability in realizing a synthesis between solicitations coming from Eastern and Muslim culture that had already manifested in Palermo, a city conquered by Pisans two years before the foundation of the Campo.

\section{In-between sacred space: place of insulations}

The unique and unrepeatable relational form of the Campo materializes one among the many possible combinations of positions and architectural figures and it is, for this reason, expression of the idea of infiniteness (Leibniz 1620). In this attitude to configure one space among the infinitely possible spaces, that is implicit in the disposition of artefacts as compositional operation, we find a settlement choice strongly appropriate to the sacred space, because the "spirit is the great manufacturer of alternatives" (Musil, 1943).

In these places of separation, the consecrated ground - no longer the canonically one defined by the temenos of the Cathedral halls, of Baptisteries, of temples - is an "in-between space" leading to a reflection about the base-rampart, as a natural element (like the Campo dei Miracoli) or an artificial one (like the Acropolis), also in following projects belonging to contemporary age. In these projects the base-rampart is an unification element for different polarities and here we can find a tensional space (Costanzo, 2015) lying between the artefacts. They are linked by proximity and by a distance/measure that are recorded by the open space, becoming itself the object of a search for exactness. This is not only a dimensional shift, from architecture to urban part, but also a conceptual shift, from limited and perfectly defined void (architectural interior space), to an open and undetermined space (urban space). If the idea of proximity and approach, from the theological point of view (at least in the Christian tradition), prevails over the idea of distance and if it is the first canon of the relationship liturgy/architecture (Valenziano, 2011), the search for exactness is linked with the utopia. Utopia of exactness, which looks like «the amplification process of certain elementary relationships from which one imagines certain macroscopic effects of life must come» (Musil, 1943), and which we can architecturally identify in the relationships established by buildings and their positions, each one identifying a sacrament or a religious action.

The modern declination of "sacredness" materialized in this place is certainly not entrusted to the artifacts' exactness, to their formal absoluteness or to the harmonious construction of their proportions that had characterized the Greek and Roman architecture (with the great paradigms of the Pantheon and the Parthenon) and that was recovered and actualized, as we have seen, in Reinassence. It essentially concerns relationships that regulate buildings' reciprocal positions, establishing the character of the sacer in its original sense of "separated" (Valenziano, 2011).

Two Italian projects from the early 2000s assume this open concept of urban space to address the theme of contemporary sacred space and in particular the relationship of coexistence between different religions. The projects by Salvatore Bisogni and Franco Purini (Bisogni, 2011; Vitale, 2019) interpret the multi-religious space as an "urban place of the Spirit" on the basis of the concept of zolla, that is an ambit in which distinct architectures are placed (Synagogue, Church, Mosque, inter-religious building) and which represents a common anthropic base as an ideal figure of the open space (Figure 8 and Figure 9). The common ground on which different sacred architectures stand, each with its position and its formal identity, is the place of their confrontation and the guarantee of their possible coexistence. It is a space separated from the condition of nature naturans extra-moenia, but also from the reality of the contemporary city, both from the historical forms of concentration and from the recent forms of dispersion. 


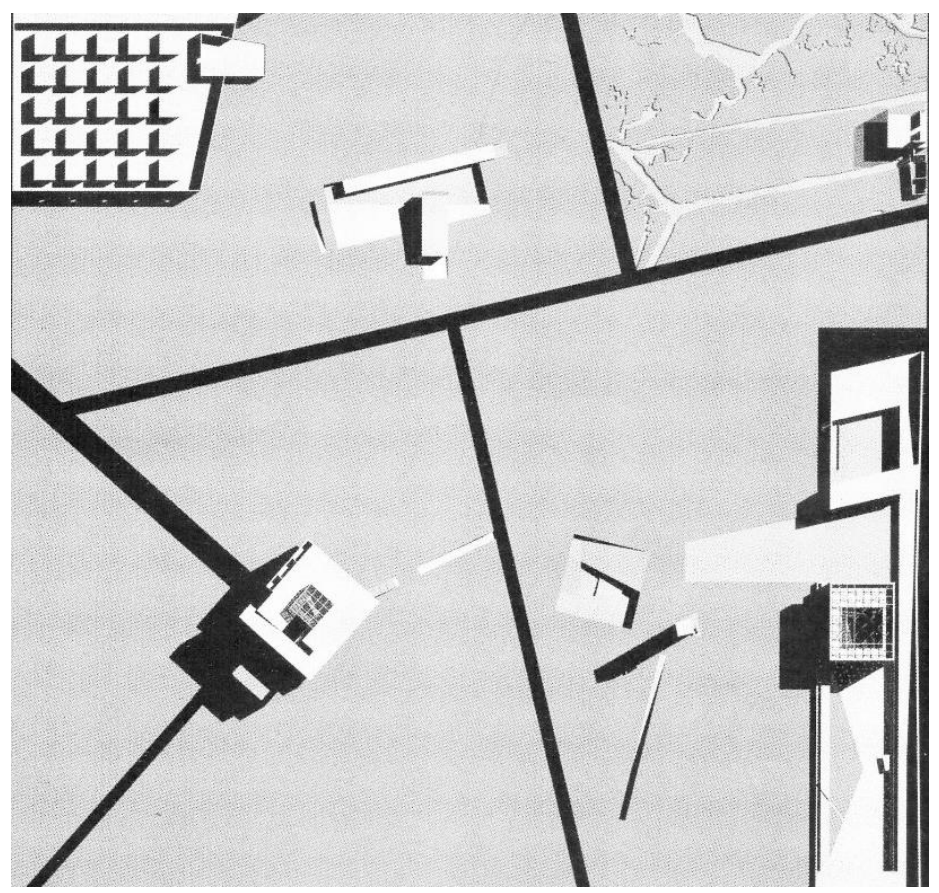

Figure 8. Mestre, Zolla of the Spirit, 2000-11, Purini project. Plan

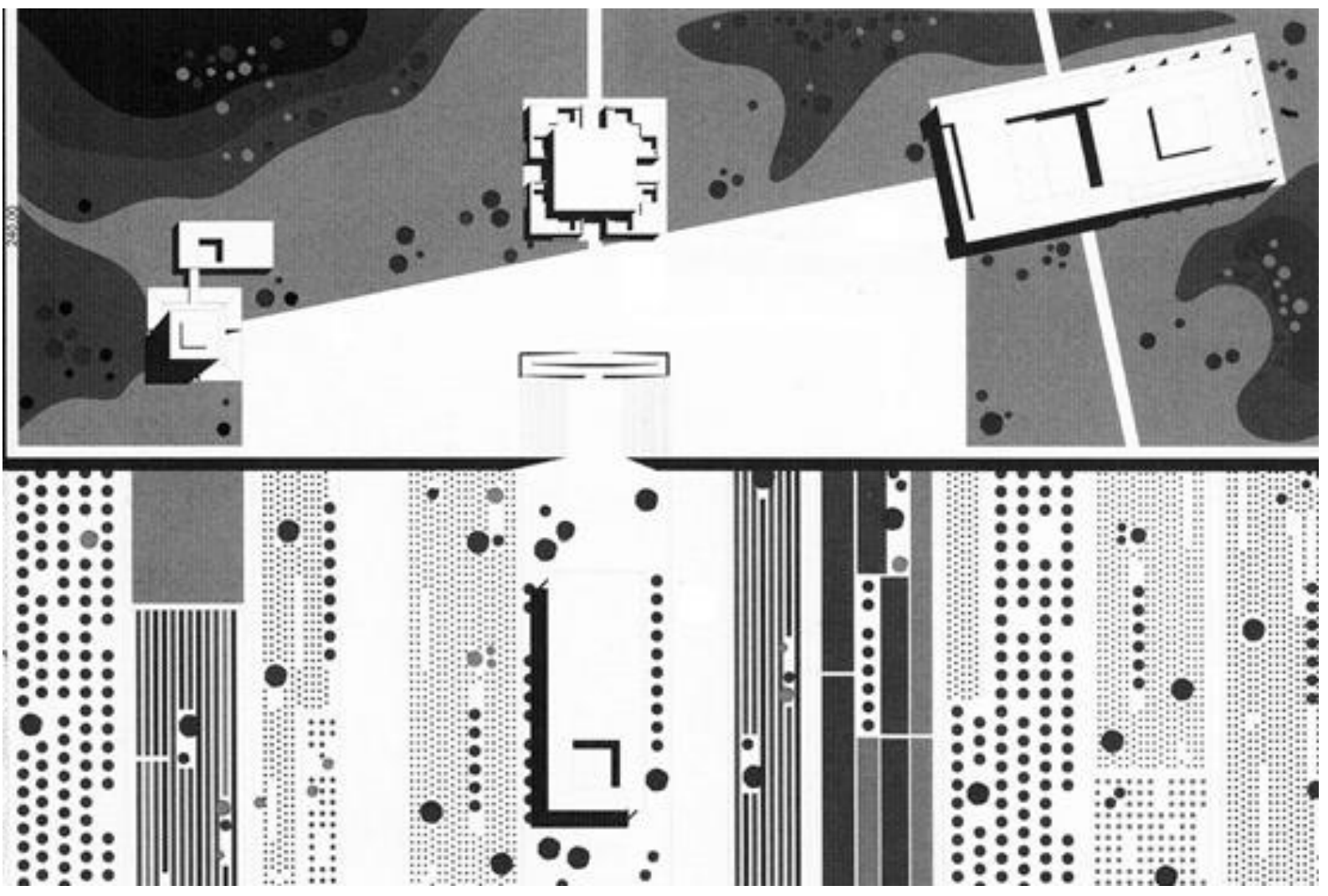

Figure 9. Ager Campanus, Zolla of the Spirit, 2000-11, Bisogni project. Plan

\section{In-between sacred space as paradigm for public space: the Le Corbusier's theorem}

After nine centuries from the foundation of the Pisan square, Le Corbusier, a master of Twentieth-Century architecture, recognizes that the Campo dei Miracoli represents a completely modern way for building urban space to be used for defining new places for collective representation. As written in his sketch of the Campo in 1934, the Suisse-French master identifies in the tumulte dans l'ensamble, guaranteed by the unitè dans le detail, the most effective possibility for his Palace of the Soviets and for his later great compositions. This reading is done by Le Corbusier on the basis of the great philosophical and literary contributions standing at the basis of modern thought 
and that have shown a deep interest for openess and indeterminateness as themes, as in cases of quoted Leibniz and Musil.

It must be said that this advancement for the construction of the city and its representative places - basically referable to the open city dispersed in nature influenced by Enlightenment culture - appears fundamental as it stood as an alternative to the line of Stadtbau conditioned by Camillo Sitte's book "Art of building the city". This text supported the idea of a closed city in which urban space was defined by formal continuity. In writing about the insulation of buildings, Sitte declared that «the effect of the building is not concentrated anywhere (...) and both the living organic integration in the environment and the creation of perspective effects are lacking [in the building, R. N.]".

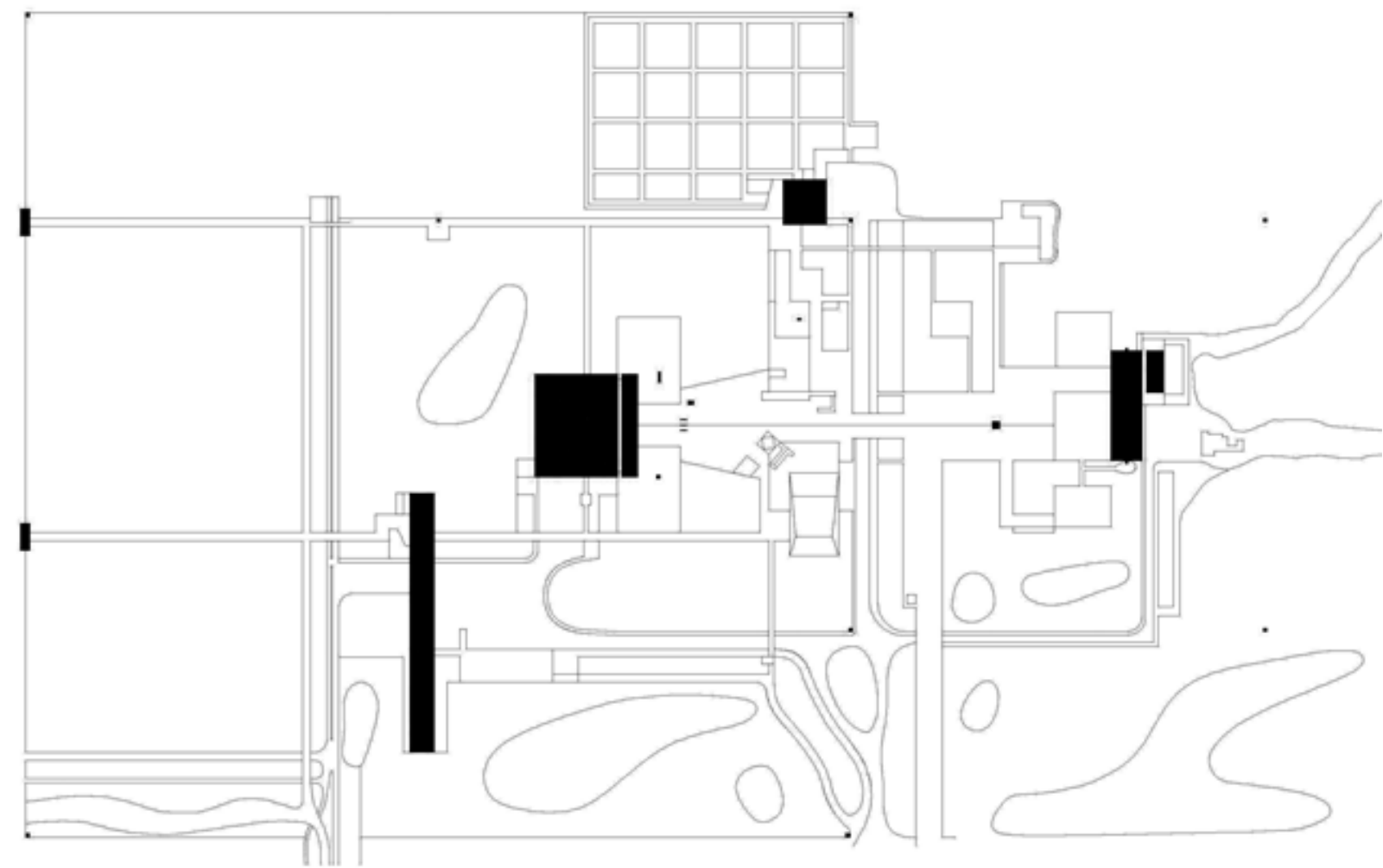

Figure 10. Chandigarh, Esplanade, 1950, Le Corbusier project. Plan (by Costanzo 2007)

The Esplanade in Chandigarh probably represents the collective space project in which Le Corbusier makes the most of the Pisan lesson (Figure 10). In his project of the new city of Chandigarh, capital city of the state of Punjab belonging to the Indian federation, the Franco-Swiss master imagines the urban part dedicated to government buildings and central institutions as a secular acropolis. This large open space is defined by a ground, in this case paved, on which the great institutional architectures face each other at a distance and take as horizon the Himalayas' profile that participates in the spatial composition. Here we find all the elements that make up the syntax of this collocative mode of constructing space: the unifying ground, the isolated and formally defined architectures, the participation of the landscape. The positions, but above all the dimensions of architectures and their reciprocal distances, are dominated by clear proportional rules which Quaroni has effectively defined as "balanced axialities" (Quaroni, 1977). In the construction of this system of relationships, the distance (arm) of the buildings (weights) from the transversal axis of the rampart, which represents the ideal visual line for connection with the mountains, increases with the increasing size of the architectures and especially with the increasing of their heights. In this way Le Corbusier seems to take geography (the mountains) as a parameter for the proportioning of the architectures and for the sizing of their relational space. The resulting space, dilated and rarefied, shows changing configurations and unexpected glimpses for the user who passes through it and therefore seems describable according to the Corbusierian category of "unspeakable space" (Le Corbusier, 1948).

Starting from the Esplanade, which can be considered as a paradigm, a recognizable genealogy of projects arises. These projects want to define the new representative places of the Big City and a renewed relationship with the territory and nature 


\section{Costanzo / Proceedings of Science and Technology}

The rarefaction and its evocation of proximity, the openness, the centrality of void whose measure/dis-measure identifies a collective dimension corresponding to the city's rank are the general qualities of the Corbusierian project and they constitute the essential conditions of discontinuous city as ideal. This one is the distinctive feature of the modern urban project materialized, as well as in many works by French-Swiss master, in numerous other projects, such as the Berlin Kulturforum by Hans Scharoun or the continuous researches by Ludwig Mies Van Der Rohe and Ludwig Hilberseimer (1927). In the research conducted by this last author about the civil public space, it is evident that the modern theory of secular space profoundly draws from different applications of sacred space, as evidenced by the continuous studies that the German urban planner has carried out on the Greek city's religious spaces with particular attention to the Hellenistic period. Although related to secular themes, they start from conditions we have recognized as specific features of religious space, to conceive a new "sacred dimension", that is "difference", of the civil space.

\section{References}

Alberti, L.B. (1989). De Re Aedificatoria. Milano, Italy, Il Polifilo.

Bisogni, S. (Ed). (2011). Ricerche in architettura. La zolla nella dispersione delle aree metropolitane. Napoli, Italy, Edizioni Scientifiche Italiane. Bodei, R. (2016). Limite. Bologna, Italy, Il Mulino.

Casciato, M. (Ed). (2003). Le Corbusier a Chandigarh. Ritratto di una città moderna. Roma, Italy, Edizioni Kappa.

Costanzo F. (2015). Discontinua urbani. Dispositio e città nel Novecento. FAMagazine, 32, 36-48.

Costanzo, F. (2007). L'architettura del Campo: la composizione architettonica per le nuove centralità territoriali. Napoli, Italy, Edizioni Scientifiche Italiane.

Costanzo, F. (2011). Infinitum Secundum Multitudinem. Il canone compositivo e le infinite configurazioni dello spazio sacro. In Sicignano, E. (Ed). L'architettura dello spazio sacro. Soveria Mannelli, Italy, Rubbettino.

Doxiadis, CA. (1972). Architectural Space in Ancient Greece. Cambridge, USA, The MIT Press.

Günay, R. (1998). Sinan. The architect and his works. Istanbul, Turkey, Yapi Yayin.

Hilberseimer, L. (1927). Groszstadt Architektur. Stuttgart, Germany, Joseph Hoffmann.

Le Corbusier. (1948) Ineffable space. In Le Corbusier. New World of Space. Boston - New York, USA, Raynal \& Hitchcock.

Leibniz, G.W. (1627), Monadologia.

Leonardo da Vinci (2002), Scritti artistici e tecnici. Milano, Italy, BUR-Rcs.

Martì Arìs, C. (1990). Le variazioni dell'identità. Milano, Italy, Clup.

Musil, R. (1943). Der Mann ohne Eigenschaften. Berlin, Germany, Rowohlt Verlag.

Quaroni, L. (1977). Progettare un edificio. Milano, Italy, Mazzotta Editore.

Valenziano, C. (2011) Architettura e liturgia. In Sicignano, E. (Ed). L'architettura dello spazio sacro. Soveria Mannelli, Italy, Rubbettino. .

Vitale, D. (2019). Salvatore Bisogni. Architetture immaginate. Napoli, Italy, Clean. 